\title{
IS RETIREMENT A GOOD MOMENT FOR BECOMING COMPUTING LITERATE?
}

\author{
Cristina Vilaplana Prieto \\ Universidad de Murcia (SPAIN) cvilaplana@um.es
}

\begin{abstract}
The aim of this paper is to disentangle the characteristics of older people who know computer science and test if older people consider retirement as a good moment for learning this issue. We use data from the Survey of Living Conditions of Older People (2010) carried out by the IMSERSO to individuals aged 65 and older. Available information allow us to differentiate among three categories of users: (1) those who knew computer science before getting retired "pre-users" $(6.79 \%)$, (2) those who learnt it after retirement "postusers" $(2.76 \%)$ and (3) those who have never expressed interest in it "never users" (90.45\%). As compared to "never users", people qualified as "pre-users" or "post-users" are to a large extent male, aged 65-69, with high school or college education, income higher than $900 € /$ month and, usually combine this activity with others such as tourism, sports and volunteerism. To determine which variables affect the probability of becoming "post-user" we estimate a bivariate probit model with sample selection. The probability of becoming "post-user" increases by $151 \%$ for those who consider that retirement is "an opportunity for pursuing your particular hobbies" and it increases by $71 \%$ for those who report that their main fear for the future is to loose memory. However, living in a municipality with less than 5,000 inhabitants or being housekeeper during working life decreases this probability. On the other hand, the most well-suited moment for becoming familiar with computer science is just after retirement because the probability of becoming "post-user" increases by $245 \%$ for the cohort aged $65-59$.
\end{abstract}

Keywords: Older people, computer science, internet, bivariate probit model, sample selection.

\section{DATA AND DESCRIPTIVE STATISTICS}

Data used for this study come from the "Survey of Living Conditions of Older People", carried out by the Institute of Older People and Social Services (Instituto de Mayores y Servicios Sociales; IMSERSO) in 2010. It is a survey conducted by telephone interview to 2,535 people aged 65 and older living in Spain (except Ceuta and Melilla). The sample was designed by simple random sampling using the white pages directory and with some pre-defined variables (age, gender, size of municipality and Autonomous Community). Respondents answered a structured questionnaire composed by closed questions and divided in the following sections: (1) socio-demographic characteristics; (2) dwelling conditions; (3) distribution of time; (4) health status; (5) healthcare and long-term care; (6) income and consumption; (7) citizenship and social participation; (8) aging as a vital experience.

Inside the module of "Distribution of time", the respondent is asked if he is computer literate and if he uses the computer (with or without connection to internet). We observe that $9,55 \%$ of respondents answer that they can use a computer, which represents a population of 762.311 computer-literate individuals (aged 65 and older). In 2006, the previous wave of this same survey (Survey of Living Conditions of Older People, 2006) pointed to $3,2 \%$ of computer-literate people among population aged 65 and older. Therefore, in four years, the percentage of computer users have nearly tripled. For the following analysis we will concentrate in the survey for 2010. It is not possible to analyse both surveys together because the samples of 
respondents interviewed are different and because some questions have changed.

To take an idea of the degree of computer literacy among the Spanish population, Table 1 compares the percentage of computer-literacy by age cohort. In this case, we have combined information from two surveys: the Survey of Time Use (2009) for age cohorts between 15 and 64 years and the Survey of Living Conditions of Older People (2010) for the cohort aged 65 and older. The Survey of Time Use (2009) was performed by the National Institute of Statistics and gathers information of all activities selected individuals a whole day. Therefore it constitutes a perfect record of each single activity performed during a screen of 24 hours. We observe that the lowest percentage of users corresponds to the oldest cohort followed by those aged 44-55 years. By the contrary, young people aged 16-24 years exhibit the greatest percentage of users.

Table 1. Percentage of computer users by age cohorts

\begin{tabular}{|l|c|}
\hline & Computer users (\%) \\
\hline $10-15$ years & $34,4 \%$ \\
\hline $16-24$ years & $43,9 \%$ \\
\hline $25-44$ years & $22,8 \%$ \\
\hline $44-55$ years & $15,4 \%$ \\
\hline $65-+$ years & $9,3 \%$ \\
\hline
\end{tabular}

Source: Survey of Time Use (2009); Survey of Living Conditions of Older People (2010)

Continuing with the analysis of the questionnaire of the Survey of Living Conditions of Older People (2010); the respondent is also required to precise if he has started some new activity or has discovered a new hobby after retirement. One of the possibilities is "computer science" and we appreciate that $2,76 \%$ of the respondents have marked this option. These two questions (if they are computer literate and if they learnt computer science after retirement) allow as to distinguish which individuals already used the computer before getting retired and which individuals have become computer literate after retirement.

With the purpose of simplifying the notation, we define the following variables:

$>$ "Pre-user": binary indicator that takes the value 1 if the individual used the computer before becoming retired.

D "Post-user": binary user that takes the value 1 if the individual has become computer literate after retirement

> "No-user": binary indicator that takes the value 1 if the individual has never used the computer (neither before nor after retirement).

Figure 1 describes the composition of the sample according to these variables. We have not defined a fourth variable for those individuals who are computer literate but have stopped using the computer after retirement, because we have checked that all the individuals included in the category of "pre-users" continue using the computer at least once per week. 


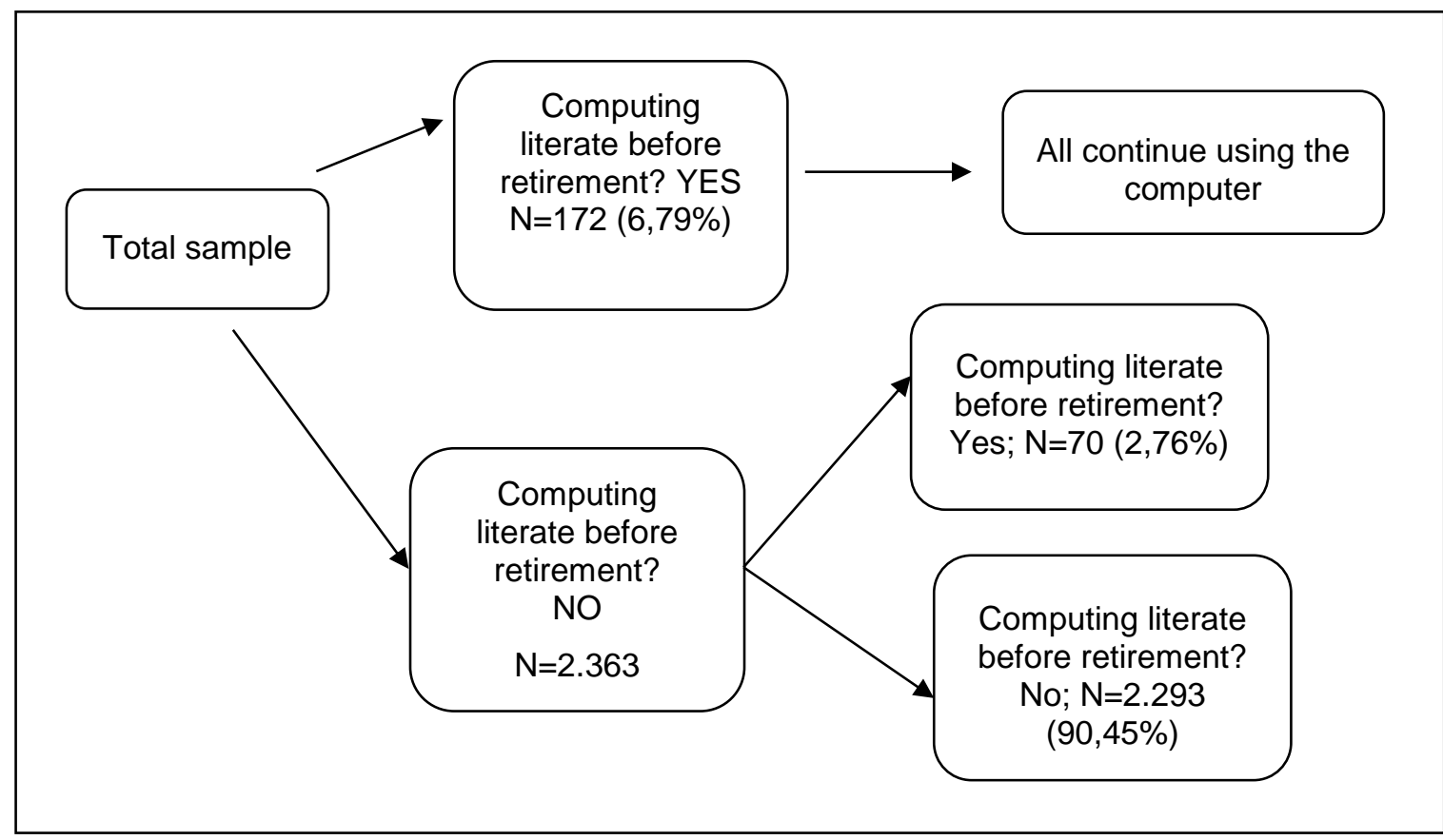

Figure 1. Distribution of the sample

Table 2 shows the descriptive statistics for the three-categories defined previously. The comparison of "users" ("pre-users" and "post-users") with respect to "no-users" reveals some differentiated sociodemographic characteristics. The percentage of males is higher among "users" $(58,35 \%$ with respect to $40,56 \%$ for "no-users"). Computer-users are also characterized by a higher concentration in the cohort 65-59 years $(53,42 \%$ with respect to $21,44 \%)$, with personal monthly income higher than $900 € /$ month $(45,89 \%$ with respect to $12,35 \%)$. By the contrary, "users" do not tend to live in municipalities with less than 5,000 inhabitants $(5,84 \%$ with respect to $22,80 \%)$.

Regarding personal hobbies, "users" tend to show a more pro-active behaviour: playing sports $(42,49 \%$ as opposed to $25,12 \%$ for "no-users"), tourism $(20,09 \%$ as opposed to $7,50 \%)$ and volunteerism $(16,88 \%$ as opposed to $8,37 \%$ ).

The level of education is substantially different between both groups: $61,58 \%$ of "users" have finished high school or college education whereas, $75,97 \%$ of "no-users" have not even finished elementary education. On the other hand, $31,59 \%$ of "users" can speak at least one foreign language (english, french, german or italian) as opposed to only $3,74 \%$ for the case of "no-users"

Table 2. Descriptive Statistics

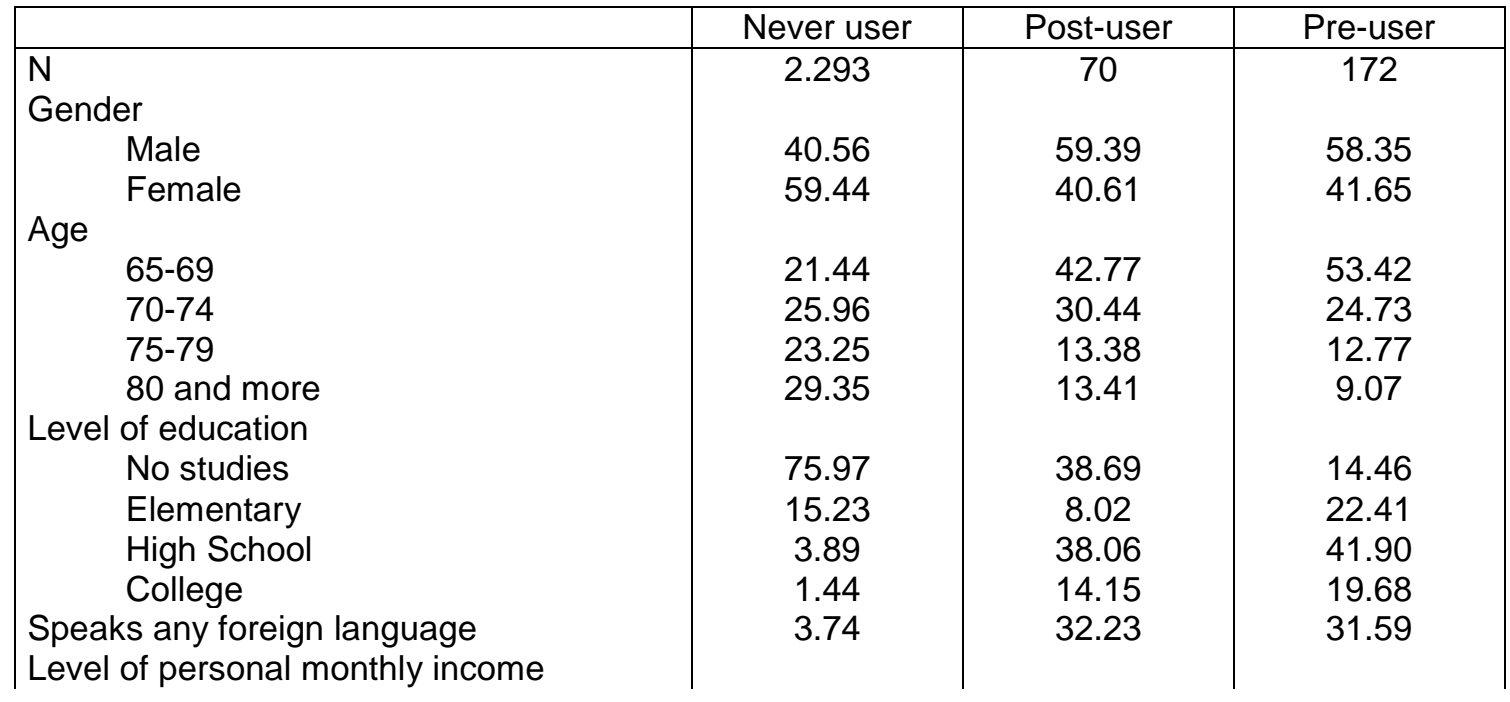




\begin{tabular}{|c|c|c|c|}
\hline Less than $300 €$ & 18.12 & 21.25 & 13.60 \\
\hline Between $300 €$ and $600 €$ & 36.01 & 6.36 & 5.78 \\
\hline Between $600 €$ and $900 €$ & 20.89 & 33.60 & 23.90 \\
\hline Between $900 €$ and $1,200 €$ & 7.02 & 6.75 & 20.08 \\
\hline More than $1,200 €$ & 5.33 & 23.79 & 25.81 \\
\hline Size of municipality & & & \\
\hline Hasta 5,000 inhabitants & 22.80 & 1.44 & 5.84 \\
\hline $5,001-10,000$ inhabitants & 9.17 & 3.58 & 5.47 \\
\hline $10,001-20,000$ inhabitants & 10.13 & 24.21 & 9.06 \\
\hline $20,001-100,000$ inhabitants & 22.57 & 21.07 & 15.70 \\
\hline More than 100,000 inhabitants & 35.34 & 49.70 & 63.93 \\
\hline Living arrangement & & & \\
\hline Alone & 16.54 & 3.41 & 5.90 \\
\hline Spouse and children & 15.15 & 41.37 & 41.32 \\
\hline With spouse (without children) & 41.45 & 40.42 & 37.45 \\
\hline With children & 18.57 & 5.83 & 5.82 \\
\hline Alone (but he dislikes it) & 11.86 & 0.74 & 2.41 \\
\hline Before retirement & & & \\
\hline Working as employee & 42.35 & 69.51 & 68.77 \\
\hline Working as employer & 17.91 & 7.38 & 13.74 \\
\hline Houseworking & 38.60 & 22.33 & 16.88 \\
\hline Present relation with economic activity & & & \\
\hline Still working & 0.60 & 1.90 & 1.21 \\
\hline Retired (worked before) & 56.88 & 73.16 & 80.26 \\
\hline Retired (houseworking before) & 16.32 & 2.61 & 1.56 \\
\hline Houseworking & 26.04 & 22.33 & 16.78 \\
\hline News activities since retirement & & & \\
\hline Computers & 0.00 & 100.00 & 24.40 \\
\hline Tourism & 7.50 & 23.36 & 20.09 \\
\hline Courses & 0.51 & 0.00 & 1.57 \\
\hline Sports & 25.12 & 41.51 & 42.49 \\
\hline Starting a business & 1.16 & - & 0.74 \\
\hline Homecrafts & 11.70 & 11.69 & 15.64 \\
\hline Gardening & 5.18 & 5.23 & 3.78 \\
\hline Going out with friends & 6.36 & 7.38 & 6.08 \\
\hline Participation in an association & 2.52 & 3.72 & 1.79 \\
\hline Volunteerism & 8.37 & 23.21 & 16.03 \\
\hline Satisfaction with retirement & & & \\
\hline Time for doing what one wants & 15.39 & 27.34 & 29.45 \\
\hline Life has lost its sense & 11.93 & 16.42 & 12.49 \\
\hline Fears for the future & & & \\
\hline Illness & 51.96 & 54.93 & 53.92 \\
\hline Loneliness & 30.52 & 32.51 & 29.00 \\
\hline Memory loss & 7.35 & 3.57 & 3.25 \\
\hline Loosing independency & 36.54 & 40.15 & 38.19 \\
\hline Good health (self-reported) & 13.58 & 19.44 & 19.77 \\
\hline
\end{tabular}

Source: Own elaboration using the Survey of Living Conditions of Older People (2010).

As we do not have time series we can not infer any causality relationship between computer literacy and the performance of other activities. However, we can analyze if there exists a significant association between any pair of activities for each group of computer "users"/"no-users". Table 3 shows the Spearman correlation's coefficients for the subsample of individuals who used the computer before retirement. The star $\left.{ }^{*}\right)$ highlights the significant correlations at $5 \%$ of significance. We appreciate a positive and significant correlation between doing homecrafts and starting a business; between cultural activities and tourism; between religious activities and tourism; between volunteerism and looking after somebody and between voluntarism and doing homecrafts. On the other hand, there exist a negative and significant correlation between playing sports and participating in an association and between playing sports and voluntarism. 
Table 3. Spearman correlations between any pair of activities (started after retirement). Subsample of individuals who used the computer before retirement.

\begin{tabular}{|c|c|c|c|c|c|c|c|c|c|c|c|c|}
\hline & (1) & (2) & (3) & (4) & (5) & (6) & (7) & (8) & (9) & (10) & (11) & (12) \\
\hline (1) & 1 & & & & & & & & & & & \\
\hline (2) & 0.0895 & 1 & & & & & & & & & & \\
\hline (3) & -0.0494 & -0.1177 & 1 & & & & & & & & & \\
\hline (4) & 0.0984 & -0.0923 & $-0.1616^{*}$ & 1 & & & & & & & & \\
\hline (5) & 0.0931 & $0.2761^{\star}$ & -0.0988 & -0.0255 & 1 & & & & & & & \\
\hline (6) & $0.2071^{\star}$ & -0.0729 & $0.1679^{*}$ & 0.0097 & -0.0359 & 1 & & & & & & \\
\hline (7) & -0.0288 & -0.0868 & 0.0206 & -0.0519 & -0.024 & -0.0731 & 1 & & & & & \\
\hline (8) & $0.2340^{*}$ & -0.0606 & $-0.1406^{\star}$ & -0.0363 & -0.0167 & -0.0511 & -0.0341 & 1 & & & & \\
\hline (9) & -0.0351 & $0.1946^{\star}$ & -0.0697 & -0.018 & -0.0083 & -0.0253 & -0.0169 & -0.0118 & 1 & & & \\
\hline (10) & -0.0709 & $0.1661^{\star}$ & $-0.1406^{*}$ & -0.0363 & -0.0167 & -0.0511 & -0.0341 & -0.0238 & $0.4956^{\star}$ & 1 & & \\
\hline (11) & $0.1380^{\star}$ & 0.092 & -0.0694 & 0.0837 & -0.0223 & -0.0682 & -0.0455 & -0.0318 & -0.0158 & -0.0318 & 1 & \\
\hline (12) & 0.0558 & 0.0781 & -0.0322 & -0.0313 & -0.0145 & -0.0441 & -0.0294 & -0.0206 & -0.0102 & -0.0206 & $0.1973^{\star}$ & 1 \\
\hline
\end{tabular}

Source: Own elaboration using the Survey of Living Conditions of Older People (2010).

(1) Tourism; (2) homecrafts; (3) playing sports; (4) going out with friends; (5) starting a business; (6) participate in cultural activities/conferences; (7) gardening; (8) participate in an association; (9) looking after somebody (not being paid for it); (10) volunteerism; (11) going to the church, religious activities; (12) courses, Third Age University Programs.

For the subsample of post-users, in the Spearman correlation matrix we have not included "having started a business since retirement" because nobody answered in the affirmative to this question. There is a positive and significant correlation between tourism and homecrafts; between tourism and going out with friends and between participating in cultural activities and in an association. On the other hand, there is a negative correlation between playing sports and going out with friends.

Table 4. Spearman correlations between any pair of activities (started after retirement). Subsample of individuals who became computer literate after retirement.

\begin{tabular}{|c|c|c|c|c|c|c|c|c|c|c|}
\hline & (1) & (2) & (3) & (4) & (6) & (7) & (8) & (9) & (10) & (11) \\
\hline (1) & 1 & & & & & & & & & \\
\hline (2) & $0.2182^{*}$ & 1 & & & & & & & & \\
\hline (3) & -0.1006 & $-0.3000^{*}$ & 1 & & & & & & & \\
\hline (4) & $0.3308^{\star}$ & -0.1076 & $-0.2490^{*}$ & 1 & & & & & & \\
\hline (6) & -0.1191 & -0.0663 & 0.0338 & -0.055 & 1 & & & & & \\
\hline (7) & -0.0623 & -0.1076 & -0.1275 & -0.0893 & -0.055 & 1 & & & & \\
\hline (8) & -0.1191 & -0.0663 & -0.1534 & -0.055 & $0.4831^{*}$ & -0.055 & 1 & & & \\
\hline (9) & -0.0835 & -0.0465 & 0.1549 & -0.0386 & -0.0238 & -0.0386 & -0.0238 & 1 & & \\
\hline
\end{tabular}


Proceedings of ADVED 2020- 6th International Conference on Advances in Education

\begin{tabular}{|l|r|r|r|r|r|r|r|r|r|r|}
\hline $\mathbf{( 1 0 )}$ & -0.1471 & 0.156 & 0.1188 & -0.068 & -0.0419 & -0.068 & -0.0419 & -0.0294 & 1 & \\
\hline $\mathbf{( 1 1 )}$ & -0.1471 & -0.0819 & -0.1895 & -0.068 & -0.0419 & -0.068 & -0.0419 & -0.0294 & -0.0517 & 1 \\
\hline
\end{tabular}

Source: Own elaboration using the Survey of Living Conditions of Older People (2010).

(1) Tourism; (2) homecrafts; (3) playing sports; (4) going out with friends; (5) starting a business; (6) participate in cultural activities/conferences; (7) gardening; (8) participate in an association; (9) looking after somebody (not being paid for it); (10) volunteerism; (11) going to the church, religious activities; (12) courses, Third Age University Programs.

Table 5 shows the Spearman's correlations for the subsample of individuals who are computer illiterate. We observe a significant and positive correlation between tourism and playing sports (or going to the church or going to courses); between doing homecrafts and participating in cultural activities (or volunteerism); between playing sports and going out with friends (or gardening); between going out with friends and looking after somebody (or going to the church); between participating in an association and going to cultural activities (or courses). From these correlations we can infer that people who are not computer literate are not isolated from the world. Quite the opposite, the correlation coefficient between tourism and going out with friends is significant and quite large (0.2244), which indicates that computer literacy is not only a question of opportunities (knowing someone who can teach you, having the required equipment..), but also it is a question of tastes.

Table 5. Spearman correlations between any pair of activities (started after retirement). Subsample of individuals who have never used the computer (are not computer literate).

\begin{tabular}{|c|c|c|c|c|c|c|c|c|c|c|c|c|}
\hline & (1) & (2) & (3) & (4) & (5) & (6) & (7) & (8) & (9) & (10) & (11) & (12) \\
\hline (1) & 1 & & & & & & & & & & & \\
\hline (2) & $0.1279^{*}$ & 1 & & & & & & & & & & \\
\hline (3) & $0.0435^{\star}$ & 0.0137 & 1 & & & & & & & & & \\
\hline (4) & $0.2244^{\star}$ & 0.0118 & $0.0956^{\star}$ & 1 & & & & & & & & \\
\hline (5) & -0.0036 & -0.0255 & -0.0033 & $0.0841^{*}$ & 1 & & & & & & & \\
\hline (6) & 0.0198 & $0.0823^{\star}$ & 0.0183 & $0.0495^{\star}$ & -0.0142 & 1 & & & & & & \\
\hline (7) & -0.0198 & $-0.0489^{\star}$ & $0.0691^{*}$ & $-0.0349^{\star}$ & 0.0202 & $-0.0420^{*}$ & 1 & & & & & \\
\hline (8) & -0.0146 & -0.0079 & -0.0328 & -0.0105 & -0.0124 & $0.0545^{\star}$ & 0.0022 & 1 & & & & \\
\hline (9) & -0.0118 & 0.023 & 0.02 & $0.0506^{\star}$ & -0.014 & 0.0079 & $-0.0416^{*}$ & $0.0357^{\star}$ & 1 & & & \\
\hline (10) & 0.0037 & $0.0614^{\star}$ & $-0.0357^{\star}$ & -0.015 & 0.0205 & 0.0111 & $-0.0394^{\star}$ & -0.022 & $0.0483^{\star}$ & 1 & & \\
\hline (11) & $0.0801^{*}$ & 0.0302 & 0.0286 & $0.1043^{\star}$ & -0.0106 & 0.0025 & -0.0314 & 0.0082 & -0.0199 & -0.0189 & 1 & \\
\hline (12) & $0.1122^{\star}$ & -0.0195 & 0.0226 & 0.0108 & -0.0057 & -0.0108 & -0.0169 & $0.0849^{\star}$ & 0.031 & -0.0102 & -0.0081 & 1 \\
\hline
\end{tabular}

Source: Own elaboration using the Survey of Living Conditions of Older People (2010).

1. Tourism; (2) homecrafts; (3) playing sports; (4) going out with friends; (5) starting a business; (6) participate in cultural activities/conferences; (7) gardening; (8) participate in an association; (9) looking after somebody (not being paid for it); (10) volunteerism; (11) going to the church, religious activities; (12) courses, Third Age University Programs.

\section{MODEL}

We consider that the fact of being "pre-user", "post-user" or "no-user" is a consecuance of individual's decisions along a period of time. It seems quite plausible to consider that life history can be divided in two periods: before retirement and after retirement and consequently, we can build a sequential model. The first 
stage of the model is the pre-retirement model and the second stage corresponds to the post-retirement one. We will use a bivariate probit model with sample selection ([1], [2]). The advantage of this model is that it allows correlation between the unobservable variables that affect the decision of being "no-user" in the first period (before retirement) and the unobservable variables that affect the probability of becoming computer literate in the second period (after retirement).

Consequently, for each individual $\mathrm{i}=1, \ldots, \mathrm{N}$, the utility in each stage of the model $(\mathrm{t}=1,2)$ can be expressed as the sum of two components:

$$
\begin{aligned}
& t=1 \Rightarrow U_{i j 1}=\beta^{\prime}{ }_{j 1} X_{i j 1}+\varepsilon_{i j 1} \quad j=\text { "pre-user","never user" } \\
& t=2 \Rightarrow U_{i j 2}=\beta^{\prime}{ }_{j 2} X_{i j 2}+\varepsilon_{i j 2} \quad j=\text { "post-user","never user" }
\end{aligned}
$$

where $X_{i j 1}, X_{i j 2}$ refer to the observed component (socio-economic characteristic of the individual, environmental variables) and $\varepsilon_{i j 1}, \varepsilon_{i j 2}$ are random and unobservable error terms. We suppose that the error terms are distributed according to a biviariate normal distribution $\varepsilon_{i 1}, \varepsilon_{i 1} \sim N(0,0,1,1, \rho)$. Although total utility is an unobservable variable, individual choices at each stage are observable. At period 1, an individual decides to become "pre-user" when this alternative maximizes his utility at this stage. For the same reason, an individual will decide to become "post-user", when conditional on not having used computers during the period prior to retirement he decides to become familiar with computers after retirement.

$$
\operatorname{Pr} e-\text { user }_{i}=\left\{\begin{array}{l}
1 \text { if } U_{i 1}>0 \\
0 \text { otherwise }
\end{array} \quad \text { Post }- \text { user }_{i}=\left\{\begin{array}{l}
1 \text { if } U_{i 2}>0 \\
0 \text { otherwise }
\end{array}\right.\right.
$$

The corresponding likelihood function is:

$$
L=\sum_{y_{i 1}=0, y_{i 2}=1} \ln \Phi_{2}\left[-\beta_{1}^{\prime} X_{i 1}, \beta_{2}^{\prime} X_{i 2}, \rho\right]+\sum_{y_{i 1}=0, y_{i 2}=0} \ln \Phi_{2}\left[-\beta_{1}^{\prime} X_{i 1},-\beta_{2}^{\prime} X_{i 2}, \rho\right]+\sum_{y_{i 1}=1} \ln \Phi\left[\beta_{1}^{\prime} X_{i 1}\right]
$$

Regarding the explanatory variables for the decision of becoming "pre-user" $\left(X_{i 1}\right)$ we include gender, level of education, speaking any foreign language, size of municipality and previous relation with economic activity. Among the explanatory variables for the equation of becoming "post-user" $\left(X_{i 2}\right)$, we also include gender, level of education, speaking any foreign language and size of municipality, but also, we include as exclusion restrictions the level of income (after retirement), satisfaction with retirement, fears for the future, living alone and having good health status.

We have not included variables denoting other activities (homecrafts, tourism, courses...) to avoid a problem of inverse causality. For space reasons we do not show the estimated coefficients, but only the predicted

\begin{tabular}{|c|c|c|c|}
\hline Probability for baseline $=0.0082$ & $\begin{array}{l}\text { Predicted } \\
\text { probability }\end{array}$ & $p$-value & $\begin{array}{c}\text { Increase with respect } \\
\text { to baseline (\%) }\end{array}$ \\
\hline Male & 0.0102 & 0.632 & 21.81 \\
\hline $65-69$ & 0.0284 & $0.049^{* *}$ & 245.82 \\
\hline $70-74$ & 0.0188 & 0.182 & 128.08 \\
\hline $75-79$ & 0.0073 & 0.863 & -11.33 \\
\hline Size of municipality & & & \\
\hline Hasta 5,000 inhabitants & -0.0008 & $0.015^{\star *}$ & -109.43 \\
\hline $5,001-10,000$ inhabitants & 0.0057 & 0.540 & -31.99 \\
\hline $10,001-20,000$ inhabitants & 0.0324 & $0.017^{* *}$ & 285.44 \\
\hline $20,001-100,000$ inhabitants & 0.0094 & 0.820 & 12.06 \\
\hline Level of personal monthly income & & & \\
\hline Less than $300 €$ & 0.0097 & 0.814 & 18.19 \\
\hline Between $300 €$ and $600 €$ & 0.0018 & 0.138 & -77.73 \\
\hline Between $600 €$ and $900 €$ & 0.0117 & 0.474 & 42.76 \\
\hline
\end{tabular}
probabilities. Table 6 shows the predicted probability of becoming "post-user" for an established baseline, as well as the variation in the predicted probability due to changes in the explanatory variables.

Table 6. Predicted probabilities of becoming a post-user 


\begin{tabular}{|l|c|c|c|} 
Between $900 €$ and 1,200€ & 0.0033 & 0.113 & -60.11 \\
Level of education & 0.0104 & 0.660 & 26.41 \\
$\quad$ Elementary & 0.0700 & $0.007^{* * *}$ & 751.41 \\
$\quad$ High School & 0.0337 & 0.231 & 309.92 \\
College & 0.0221 & 0.014 & 169.05 \\
Speak foreign language & & & \\
Before retirement & 0.0190 & $0.032^{* *}$ & 126.86 \\
$\quad$ Working as employee & 0.0185 & $0.021^{* *}$ & 120.11 \\
$\quad$ Working as employer & 0.0211 & $0.027^{* *}$ & 151.23 \\
Satisfaction with retirement & 0.0064 & $0.036^{* *}$ & -21.67 \\
$\quad$ Time for doing what one wants & 0.0141 & $0.043^{* *}$ & 71.59 \\
Life has lost its sense & 0.0020 & $0.080^{*}$ & -75.59 \\
Afraif of loosing memory in the future & 0.0087 & 0.898 & 5.32 \\
\hline Lives alone &
\end{tabular}

$\left({ }^{* * *}\right.$ : significant at $1 \% ;{ }^{* *}$ : significant at $5 \% ;{ }^{*}$ : significant at $\left.10 \%\right)$

Base line: women, 80 years and older, without elementary studies, devoted to houseworking

The probability of becoming "post-user" increases by $245,82 \%$ between 65 and 69 years old, thus confirming that the most well suited moment for getting familiar with computer science is just after retirement. However, age is not the only relevant factor. Those people who manifest a positive attitude over retirement and believe that "retirement is an opportunity for spending time in what one really wants" show a significant increase in the probability of becoming "post-user" $(151,23 \%)$. Therefore, a positive attitude makes everybody worthy enough for computer literacy. In this sense, the loss for loosing memory in the future increases by $71,59 \%$ the probability of becoming "post-user". For these people the contact with the new technologies may be a way of preserving their mental faculties.

Regarding the level of education, people who have only attained high school education show the greatest interest for computers after retirement $(751,41 \%)$. It is worth to notice that people with college education do not show a significant interest in new technologies after retirement, either because they did not have to learn them when they were working or because computer-science does not sound appealing to them.

In terms of previous relation with economic activity, we compare people who were doing house with respect to employed individuals (employers and employees). We appreciate that people who whose only occupation was housework (mainly women) show a significant increase in the probability of becoming post-users $(+121 \%)$ with respect to previous employers or employees. However, there may be other counterbalancing forces. Regression forecast indicate that living in a municipality with less less than 5,000 inhabitants or if living alone (at the moment of the survey) decrease the probability of becoming "post-user" decreases by $109,43 \%$ and $75,59 \%$, respectively

\section{CONCLUSIONS}

The final conclusions of this paper are the following. First, the percentage of computer users among older people is very low (under 10\%). Second, most users became computer literate before retirement, and once retired, they have continued using it. Third, the probability of becoming computer literate after retirement increases among those who adopt a positive attitude over retirement (as a new and fruitful period of their lives). Fourth, regarding new technologies diffusion actions we should recommend the following:

(1) increase the geographical coverage of formative courses (including not only capitals of province and big municipalities, but also small villages and rural environments)

(2) prepare different types of programs oriented to different audiences (people with college education, people who have been working at home for many years...)

(3) mainly oriented to people aged $65-69$ years, because although there are +80 years-old users, the first years after retirement constitute a turning point for becoming computer literate.

\section{REFERENCE LIST}

[1] Greene, W. (1993). Econometric analysis. New York: MacMillan Publishing Company. 
Proceedings of ADVED 2020- 6th International Conference on Advances in Education 5-6 October 2020

[2] Van de Ven, W. P., Van Praag, B. M. (1981). The demand for deductibles in private health insurance: a probit model with sample selection. Journal of Econometrics 17, 229-252. 